\title{
Discussion on the Application of Steel Plate Concrete in Tunnel Engineering
}

\author{
Xiaoming LI, Wenwen DONG \\ College of City and Architecture \\ Zaozhuang University \\ Zaozhuang, China \\ e-mail: zzlxm2012@126.com,476842793@qq.com
}

\begin{abstract}
Aiming at the problems existing in the current tunnel supporting method, offered a new proposals for rock support with steel concrete structure in tunnel engineering. This paper introduces new supporting method and construction process, from the safety of the tunnel construction, schedule, waterproof, 4 aspects of bearing capacity, and the segment lining support and shotcrete support comparative analysis found that the support method can improve the tunnel engineering quality, speed up the construction progress and reduce the construction cost, for the subsequent tunnel construction supporting a new concept.
\end{abstract}

Keywords-steel plate concrete; tunnel support; construction technology; bearing capacity

\section{INTRODUCTION}

At present, NATM method and shield method are the main method of tunnel excavation in China, the corresponding tunnel supporting method were mainly shotcrete and lining support. Shotcrete is composed of shotcrete, anchor, steel net structure combined support form, it can timely support, deformation to effectively control the surrounding rock, prevent fall and collapse, give full play to the self bearing capacity of surrounding rock, but also have certain conditions, in the surrounding rock's self ability, a large area of water inflow and water, it is difficult to forming soft formation at the complexity of the construction process, and the slow construction schedule; segment lining is accompanied by the application of shield machine and the precast concrete segments are commonly used in shield tunnel lining structure, but in the process of making the corner, in the construction of the top off edge, crack, breakage and use The occurrence of cracks and other issues still affect the structure of the waterproof and durability of [1].

According to the above problems, this paper proposed a new method of tunnel supporting steel concrete supporting. This paper will introduce the new construction technology of retaining structure, and the two were analyzed in many aspects, the support method for the practical applications of the theory are given guidance and help.

\section{STEEL ENCASED CONCRETE STRUCTURE}

Steel plate concrete supporting structure with steel frame, lateral wall cylinder are composed of an annular steel plate, steel ring cast high strength concrete, concrete in three state of compression, significantly improved the mechanical properties of the cylinder wall. The concrete itself has high compressive strength, but the anti bending ability is very weak, and steel, especially steel bending capacity, good plasticity, but when pressed to instability and loss of axial compressive capacity. The steel frame steel plate concrete in structure to the advantage of the two together, the compressive strength can be doubled. At the same time because of the existence of the concrete, improve the stiffness of the steel plate, both play a role, can greatly improve the bearing capacity [2].

\section{CONSTRUCTION TECHNOLOGY OF STEEL SHEET CONCRETE SUPPORT}

Steel plate concrete supporting structure, structure embodies in the project as a whole with a certain thickness of the cylinder block. By pouring concrete $6.3 \mathrm{~m}$ diameter tunnel as an example, the medial plate perimeter I, every design section along the vertical length of 1.5 meters, beyond the size range tube, horizontal the 3 arc-shaped steel plate splicing plate, each arc length 6.6 meters, the thickness of $5 \mathrm{~mm}$. between each section of the arc-shaped steel plate by channel connection in between each segment is provided with a circle of steel reinforced structural integrity. Between the channel steel and steel plate bolt connection (even with specific figure 1, figure 2). As far as possible between the steel plate in order to prevent the leakage of the compact size, not steel plate is too large, to prevent the vibration of concrete after the water accumulation in the plate near the cylinder wall to diffuse, shadow strength.

Ring with diameter $3.5 \mathrm{~m}$ diameter of $3.15 \mathrm{~m}$ at the junction of the cylinder wall template will be blocked at the opening of the tube wall, the pouring wall closed shell and wooden or steel template can be selected, depending on the construction conditions. The connection can be connected with steel bolt and steel template, at the same time to support the auxiliary support ring. The template templates can be used 3 splicing equal arc length, the opening at the upper end of the template as the concrete near the vault mouth and vibrating mouth. At the same time uniform in each segment of each arc-shaped plate opening, as a concrete and vibrating mouth to mouth, after pouring the concrete export modified flat. Such vertical perfusion height to diameter $4 / 5$, using concrete perfusion and the vibration of the top export template. After a curved steel construction, steel skeleton of a cylinder under the wall until after welding, etc. at the beginning of the concrete to a certain degree after strong, $\mathrm{We}$ removed the template, continue to carry out the construction, 
the next phase of the cycle. So considering the influence of construction joints, can connect with the length of each piece of $400-500 \mathrm{~mm}$ concrete, steel $16-20 \mathrm{~mm}$ in diameter on the connection surface of uniform layout, prevent the two concrete cracks produced here.

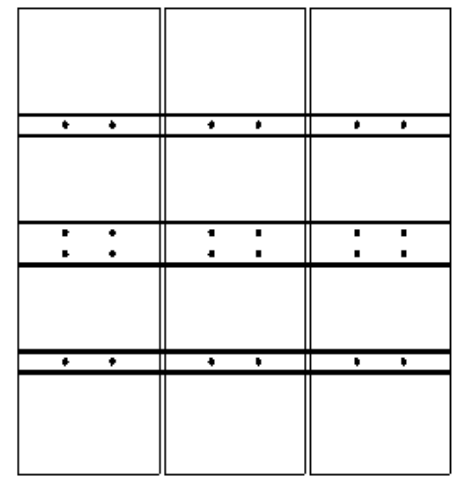

Figure 1. Connection between steel plate and transverse channel steel.

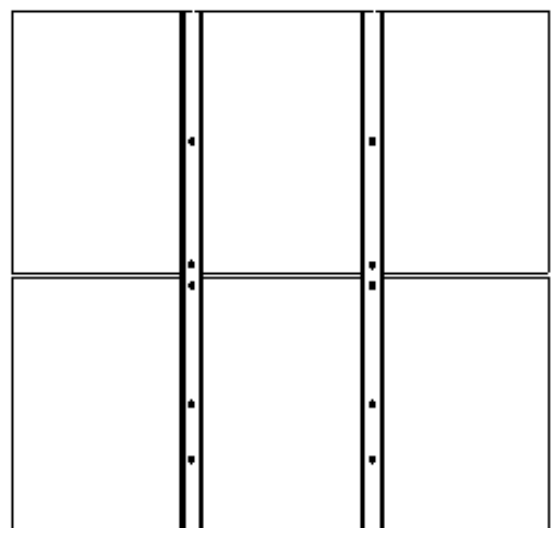

Figure 2. Connection between steel plate and longitudinal channel steel.

The new form of support, whether it is the construction of the shield machine or NATM, can be used. The shield machine in advance can be steel frame steel plate wall cylinder as Jack rely on, and save a shield machine segment automatic assembling device, reduce the cost [3].

\section{COMPARISON ANALYSIS OF THE SUPPORTING METHOD}

\section{A. Construction Safety}

Comparison of the shotcrete, on the anchor construction on the surrounding rock disturbance is relatively large, increasing the difficulty of tunnel monitoring, at the same time near the surface has the construction area by concrete curing effect, strength is difficult to quickly and ensure the safety of construction, which have increased the risk of construction personnel for the new supporting industry. The structure has an early role when lining, steel frame and steel plate quickly after installation, you can play the role of temporary support, after the completion of concrete pouring, the strength of the whole structure will improve the speed, provide safe working space for construction personnel.

\section{B. Construction Schedule}

A new method of supporting the shield method and NATM construction can be used, so the impact is mainly manifested in the time schedule of the supporting construction of tunnel length. The shield machine adopts automatic segment assembling speed is higher than that of steel and concrete construction, but the mechanical maintenance and inspection with the degree of mechanization increased more frequently [4]. NATM, a complex process undoubtedly slowed the construction progress, by contrast, steel concrete supporting the lack of large area formwork work, less process more, and affected by the concrete curing time is small, shorten the construction period.

\section{Waterproof Performance}

Methods at home and abroad are the main tunnel waterproof lining waterproofing, waterproofing and drainage of several commonly used methods of waterproof grouting waterproofing drainage tunnel. Waterproof methods are applicable for the implementation of the three tunnel is little difference, here no longer.

Waterproof lining, segment joint is the main position of shield tunnel seepage Water Leakage. By the domestic expansion of water level and tunnel waterproof materials research and development requirements, sometimes the need for 2 waterproof lining, will undoubtedly increase the cost of construction. The main method of NATM waterproof composite lining, single lining, the lining has the following problems: early support is difficult to protect; connection between waterproof board cannot be ensured, the welding process requirements; fixed mode of waterproof board in the tunnel wall is difficult to guarantee; two when the lining construction of the waterproof plate through [5].

Steel plate concrete supporting structure, can realize the seamless joint of concrete, to avoid flooding, and that the same single lining, but eliminates the single lining design of concrete material itself, it only needs to use the high impermeability of waterproof concrete grade ( $>\mathrm{S} 8$ ), to improve the waterproof performance of lining itself.

\section{Carrying Capacity}

Overview of the hypothesis of a project, in the calculation, the ground load for I, the buried depth of the tunnel is $9.0 \mathrm{~m}$, soil bulk density for I, tunnel is located in the clay layer, the lateral pressure coefficient is 0.6 , coefficient of subgrade for I, tunnel excavation diameter is $6.3 \mathrm{~m}$, according to the soil cost-effective, concrete C50.

To establish the model by ANSYE finite element software, internal force analysis model with homogeneous ring model to simulate the steel tube and concrete wall precast reinforced concrete segment and deformation, the internal force and deformation range, provide the basis for the design of shield tunnel lining structure.

The former as an example, to simulate the concrete lining structure of steel frame steel plate with BEAM3 beam element model, BEAM3WE 2D elastic beam element model is divided into 60 spring elements, each spring element with 2 nodes connected, one end connected with the surrounding 
rock and lining structure, one end connected to the outer lining structure the surrounding nodes on 1-60 under X.Y direction node stress [6]. Specific model is shown in Figure 3.

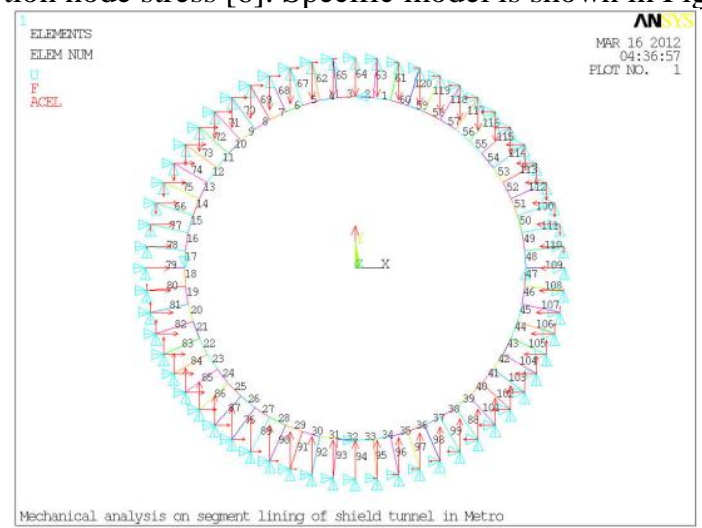

Figure 3. Finite element model with load and boundary conditions.

After solving the ANSYS post processing work by steel and concrete supporting structure and reinforced concrete segment retaining structure in $350 \mathrm{~mm}$ wall thickness, bending moment, each node structure of the shear, axial force and displacement value, the value of each node size, you can use the command "prefab, smis6, smis12, smis1, smis7, smis2. Smis8" and "PRNSOL, DOF" value map, limited space is no longer posted, calculated only in Table 1 lists some results.

TABLE I. COMPARISON OF THE FINITE ELEMENT CALCULATION RESULTS

\begin{tabular}{cccc}
\hline $\begin{array}{c}\text { Structure } \\
\text { Type }\end{array}$ & $\begin{array}{c}\text { Maximum } \\
\text { compressive } \\
\text { strain } / \mathrm{Mpa}\end{array}$ & $\begin{array}{c}\text { Maximum } \\
\text { tension stress } \\
\text { /Mpa }\end{array}$ & $\begin{array}{c}\text { Maximum } \\
\text { deformation } \\
\text { value/mm }\end{array}$ \\
\hline $\begin{array}{c}\text { Steel Plate Concrete } \\
\text { Support }\end{array}$ & 14.4 & 1.75 & 0.48 \\
$\begin{array}{c}\text { Reinforced } \\
\text { Concrete Segment }\end{array}$ & 15.8 & 2.43 & 0.87 \\
\hline
\end{tabular}

The deformation scale can be seen in the 1 node concrete lining plate of maximum displacement is $0.48 \mathrm{~mm}$ and the maximum compressive stress is $14.4 \mathrm{Mpa}$, the maximum tensile stress is $1.75 \mathrm{Mpa}$, from the "concrete structure design code > can find out the design of C50 concrete compressive strength value is $23.1 \mathrm{Mpa}$, the tensile strength design value is $1.89 \mathrm{Mpa}$, it can be seen that the compressive and tensile stresses in the concrete strength design of C50 value range is consistent with the requirements. At the same time three values are less than the precast reinforced concrete lining structure.

$350 \mathrm{~mm}$ thick reinforced concrete segment supporting structure of the maximum tensile stress is greater than $2.43 \mathrm{Mpa}$, steel plate and concrete $1.78 \mathrm{Mpa}$, was not the same as one of the reasons and the stiffness of the concrete lining structure, the stiffness of the steel plate as the reinforced concrete segment (after calculation, with wall thickness under the conditions of steel volume ratio for $1: 1.44$, the amount of steel, steel plate) too much to bear the tension than more important than steel making.

\section{CONCLUSION}

(1) Steel plate concrete in the production and construction technology of tunnel support is feasible.

(2) Can reduce the risk of the tunnel operation, improve the construction schedule.

(3) Waterproof performance, avoid the seam Water Leakage of segment lining, and improve the waterproof ability of a lining, compared with single lining waterproof, simple construction process, strong operability.

(4) When the section size of the same, steel plate and concrete supporting structure of reinforced concrete lining structure of steel consumption, although some more, but can meet the requirements for supporting the good, the internal force distribution optimization of lining structure, reduce the deformation of the tunnel.

\section{REFERENCES}

[1] Liu F J, Zu H H, Liao S M, etal. "Application study on shield tunnel lining segment of fibre reinforced concrete". Chinese Journal of Underground Space and Engineering, vol. 3, pp. 83-841, March 2007

[2] Wei Z B,Zhang X P ,Wang T C, etal. "Performance of steeI-concrete composite sIab with stiffening ribs made of section steel".JournaI of BuiIding Structures, vol. 27, pp. 77-82, January 2010

[3] Ahang X J, Liu W N, Lu M L.etal. "Problems and solutions of shield tunneling for Beijing metro". Chian Civil Eegineeing Journal, vol. 10, pp. 93-97, Oct2012

[4] Wang Z X. "Durability of shield tunnel".Underg round Engineering and Tunnels, vol. 6, pp. 2-5, February2008

[5] Yuan Y, Jiang X M, Zhou X, etal. "Current state of tunnel water pr oofing technique in china". World Tunnelling. vol. 4, pp. 41-44, August 2009

[6] Li L M. ANSYS finite element analysis of practical tutorial. Beijing : Tsinghua University press, 2005 . 